\title{
Human pancreatic islet transplantation: an update and description of the establishment of a pancreatic islet isolation laboratory
}

Jakeline Rheinheimer ${ }^{1,2}$, Andrea C. Bauer', Sandra P. Silveiro ${ }^{1,2}$, Aline A. F. Estivalet ${ }^{1}$, Ana P. Bouças ${ }^{1,2}$, Annelise R. Rosa ${ }^{1}$, Bianca M. de Souza ${ }^{1,2}$, Fernanda S. de Oliveira' ${ }^{1}$ Lavínia A. Cruz' ${ }^{1}$ Letícia A. Brondani ${ }^{1,2}$, Mirela J. Azevedo ${ }^{2}$, Natália E. Lemos ${ }^{1,2}$, Rodrigo Carlessi ${ }^{1,2}$,

Taís S. Assmann ${ }^{1,2}$, Jorge L. Gross ${ }^{1,2}$, Cristiane B. Leitão',2, Daisy Crispim ${ }^{1,2}$

\begin{abstract}
Type 1 diabetes mellitus (T1DM) is associated with chronic complications that lead to high morbidity and mortality rates in young adults of productive age. Intensive insulin therapy has been able to reduce the likelihood of the development of chronic diabetes complications. However, this treatment is still associated with an increased incidence of hypoglycemia. In patients with "brittle T1DM", who have severe hypoglycemia without adrenergic symptoms (hypoglycemia unawareness), islet transplantation may be a therapeutic option to restore both insulin secretion and hypoglycemic perception. The Edmonton group demonstrated that most patients who received islet infusions from more than one donor and were treated with steroid-free immunosuppressive drugs displayed a considerable decline in the initial insulin independence rates at eight years following the transplantation, but showed permanent $\mathrm{C}$-peptide secretion, which facilitated glycemic control and protected patients against hypoglycemic episodes. Recently, data published by the Collaborative Islet Transplant Registry (CITR) has revealed that approximately $50 \%$ of the patients who undergo islet transplantation are insulin independent after a 3-year follow-up. Therefore, islet transplantation is able to successfully decrease plasma glucose and $\mathrm{HbA} 1 \mathrm{c}$ levels, the occurrence of severe hypoglycemia, and improve patient quality of life. The goal of this paper was to review the human islet isolation and transplantation processes, and to describe the establishment of a human islet isolation laboratory at the Endocrine Division of the Hospital de Clínicas de Porto Alegre - Rio Grande do Sul, Brazil. Arch Endocrinol Metab. 2015;59(2):161-70
\end{abstract}

Keywords

Human pancreatic islets; type 1 diabetes mellitus; islet isolation; islet transplantation
1 Laboratory of Human Pancreatic Islet Biology; Endocrinology Division, Hospital de Clínicas de Porto Alegre (HCPA), Porto Alegre, RS, Brazil ${ }^{2}$ Post-Graduate Program in Medical Sciences: Endocrinology, Universidade Federal do Rio Grande do Sul (UFRGS), Porto Alegre, RS, Brazil

Correspondence to:

Daisy Crispim

Rua Ramiro Barcelos, 2350

prédio $12,4^{\circ}$ andar

90035-003 - Porto Alegre, RS, Brazil daisy_crispim@hotmail.com

Received on May/6/2014 Accepted on Feb/23/2015

DOI: $10.1590 / 2359-3997000000030$

\section{INTRODUCTION}

$\mathrm{T}$ ype 1 diabetes mellitus (TIDM) is responsible for approximately $10 \%$ of all diabetes cases worldwide. This disease is caused by autoimmune destruction of pancreatic $\beta$ cells, which leads to complete insulin deficiency and fates patients to require exogenous insulin to survive $(1,2)$. Although significant advances in the treatment of TIDM have been seen in recent decades $(3,4)$, this disease still leads to chronic complications, which are associated with high morbidity and mortality in individuals in a productive age (5). Moreover, a number of TIDM patients present "brittle TIDM", which is characterized by unpredictable glycemic oscillations over short periods of time, with sudden epi- sodes of hyperglycemia followed by severe hypoglycemia, which may evolve to convulsions, coma, and even death (6). The "brittle TIDM" treatment still represents a major challenge for the clinicians, and there is no consensus indicating the optimal treatment for this condition. The replacement of $\beta$ cells through wholepancreas or islet transplantation is the only manner to restore endogenous insulin secretion and the awareness of hypoglycemic symptoms and represents an appealing treatment option for these patients $(7,8)$.

Whole-pancreas transplantation results in adequate glycemic control and is able to prevent diabetic chronic complications, being recommended for TIDM patients with end-stage kidney disease, at the same time as the kidney transplant or after it $(9,10)$. Although, pancreas- 
transplanted patients show high rates of long-term survival, this procedure is usually not recommended to TIDM patients who do not require a kidney transplantation, since its morbidity and mortality rates are as high as those associated with other major surgical procedure $(7,9,10)$. In this context, allogeneic islet transplantation has become an interesting option for "brittle TIDM" patients, as it consists of a cell infusion procedure, which is not associated with major complications. This occurs because the islets are infused directly into the liver through the portal vein (Figure 1) using interventional radiology techniques (7). According to the Collaborative Islet Transplant Registry (CITR), the risk of peri-procedure complications associated with islet infusion is 20 times lower than that observed after whole-pancreas transplantation (11).

Therefore, the aim of the present study was to review the current literature regarding pancreatic islet isolation and transplantation in TIDM patients as well as evaluate the current status of this procedure in the international health scenario. Furthermore, we also described the development of a laboratory for human pancreatic islet isolation in the Endocrine Division of the Hospital de Clínicas de Porto Alegre (HCPA; Porto Alegre, Brazil). Currently, this laboratory is equipped and technically prepared to begin islet transplantation in TIDM patients who underwent kidney transplantation.

\section{HISTORICAL ASPECTS}

Although pancreatic islet transplantation was first attempted in 1893 (12), it was only in 1972 that Lacy and cols. (13) managed to reverse hyperglycemia in diabetic rodents through the infusion of healthy islets.
In the 1980s, the use of autologous islet transplantation in patients who underwent total pancreatectomy for untreatable pain as a result of chronic pancreatitis was reported (14). These patients were able to maintain insulin independence for up to 13 years following the transplant (15). Since these data were first published, the use of islet transplantation for the treatment of TIDM has been investigated by several researchers, who sought a possible cure for this condition.

Nevertheless, the first attempts at allogeneic pancreatic islet transplantation in humans did not produce promising results, leading to insulin independence rates of only $10 \%(16,17)$. Data obtained from the Islet Transplant Registry (ITR) revealed that a total of 493 islet transplantations were performed worldwide between the years 1893 and 2000, showing decreasing rates of insulin independence over the time following the transplant: $66 \%$ after 1 month, $40 \%$ after 1 year, $22 \%$ after 2 years, $11 \%$ after 3 years, $6 \%$ after 4 years and only $2 \%$ after 5 years (18). Although semi-automated islet isolation was made possible in 1989 by the research group led by Dr. Camillo Ricordi, in Miami, USA (19), it was only in the year 2000, after the creation of the Edmonton protocol, that islet transplantation began to achieve more promising results: an insulin independence rate of $100 \%$ was achieved after 1 year post transplant in seven patients with TIDM (20). The improvement in achieving insulin-independence with this protocol was attributed to the following factors: use of corticoid-free immunosuppressive protocols (induction with daclizumab and maintenance with sirolimus and a low dose of tacrolimus), and multiple islet infusions from different donors, in order to increase the mass of transplanted islets (20). In 2005, the same group published the results of a five-year follow-up of 65 patients

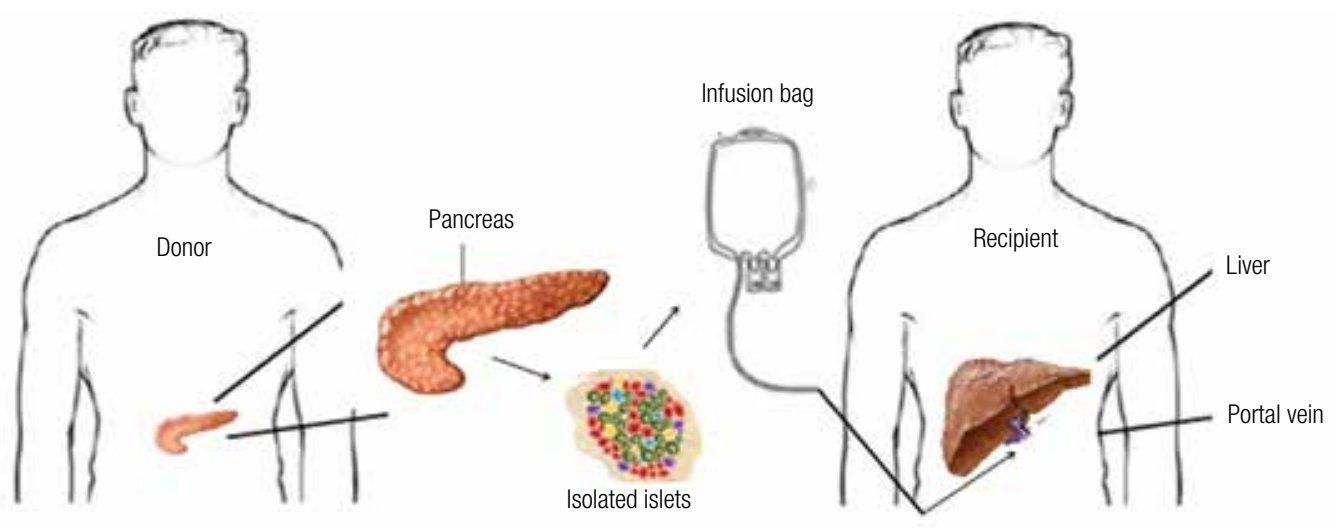

Figure 1. Infusion of human pancreatic islets into the portal vein of a recipient with type 1 diabetes mellitus. 
who had undergone islet transplantation. The mean duration of insulin independence was 15 months, with only $10 \%$ of patients remaining insulin-free for more than 5 years (21). However, it is important to note that $80 \%$ of patients had partial graft function, with detectable C-peptide secretion, contributing to the improvement of glycemic control and to the reduction in the number of hypoglycemic episodes.

The Edmonton protocol was later replicated in a multicenter study organized by the Immune Tolerance Network, which involved 36 patients with TIDM from nine centers in the USA and Europe (22). Only $13.8 \%$ of patients remained insulin-free after 2 years, although those who maintained partial graft function had a substantial improvement in metabolic control and significant lower rates of hypoglycemia (22). Success rates varied widely between centers, so that those with greater experience in the area obtained the best results, with approximately $80 \%$ of patients maintaining insulin independence after one year (22). These findings led to a new definition of the objectives and outcomes associated with islet transplantation. The main goal of islet transplantation is insulin independence and, therefore, procedures are considered completely successful whenever this outcome is achieved. However, when the transplant leads to improved glycemic control and to the reduction or elimination of severe hypoglycemic episodes, even if exogenous insulin use is still required in low doses, the procedure is considered partially successful. Individuals with partial graft function (defined by C-peptide levels $>0.5 \mathrm{ng} / \mathrm{mL}$ ) maintained their glycemic control much better than those with total graft loss (absence of C-peptide secretion) (HbAlc: 6.7 vs. 9.0\%, $\mathrm{P}=0.025$ ) and required significantly lower doses of insulin following the transplant than in the pre-transplant period $(0.34$ vs. 0.66 insulin units $/ \mathrm{kg} /$ day, $\mathrm{P}=0.001)$, as demonstrated in a fiveyear follow-up study (21).

These encouraging results led to a significant increase in the number of islet transplantations performed in all existing research centers, and motivated the establishment of further transplantation centers around the world (http://citregistry.org). The CITR was also created in an attempt to monitor the progress of islet transplantation technology and to ensure greater safety in such procedures through the registration, analysis and publication of data regarding all islet transplantation performed in North America as well as in some European and Australian locations. A total of 76 cen- ters conducted islet transplantation in the year 2005 (23) and, until May 2011, 730 patients had undergone such procedure (24). A number of countries, such as Canada, Switzerland, Australia, Japan, England and Belgium, already consider islet transplantation to be an acceptable treatment option for patients with "brittle TIDM". In these countries, such procedure is covered by public and/or private health services $(25,26)$. However, in many other countries, including USA, islet transplantation is still performed on an experimental basis (phase 3 clinical trials) (27). In the USA, islet transplantation is expected to be approved as a treatment option for "brittle T1DM" in 2015, following the end of a large multicenter clinical trial, which is currently being evaluated by the Food and Drug Administration (FDA).

Islet transplantation has led to progressively better results over recent years. A recent CITR report assessed the outcomes of 677 patients who had undergone islet transplantations between the years 1999 and 2010 . Patients were divided into three groups according to the period their surgeries were performed: "Early Era" (1999-2002), "Mid Era" (2003-2006) and "Recent Era" (2007-2010). Five main outcomes were assessed: presence of C-peptide secretion, decrease in $\mathrm{HbAlc}$ levels, stable fasting glycemia, insulin independence and frequency of severe hypoglycemia (11). Patients who underwent transplantations in the "Recent Era" had significantly better outcomes, and achieved an insulin independence rate of almost $50 \%$ three years after the transplant $(11,24)$. This result may be attributed to the improvement of islet isolation and islet culture techniques, as well as to the improvement of immunosuppressive regimens, more careful patient selection and increased knowledge and understanding of $\beta$ cell characteristics and requirements (11). The latest data obtained for graft survival at 5 years after islet transplantation have shown a significant increase in insulin independence rate. In some studies, $70 \%$ of insulin independence has been achieved in 7 years of follow-up, so far (28). These numbers are similar to those achieved with pancreas transplant alone in the same period (29).

A search for open trials on the Clinical Trials website (www.clinicaltrials.gov), performed in January 2014 using the keyword "islet transplantation", identified 34 studies which are currently recruiting patients for such procedure. These studies include investigations of immunosuppressive drugs following allogeneic islet transplantation, the outcomes of encapsulated islet trans- 
plantations and the applicability of autologous islet transplantation in cases of total pancreatectomy. None of these investigations are currently being conducted in South America. At the time of writing this paper, the Islet Transplant Program at the University of Grenoble, France, is conducting the first randomized clinical trial to compare the outcomes of islet transplantation with those on standard clinical treatment for TIDM (TRIMECO, http://clinicaltrials.gov).

\section{ISOLATION OF HUMAN PANCREATIC ISLETS}

The process of islet isolation involves the extraction of insulin-producing cells from the pancreas, while preserving their structural and functional integrity (30). Islet isolation methods have become increasingly sophisticated over the past three decades (7) and advances in this area are at least partly attributable to the use of a semi-automated method of controlled pancreatic digestion developed by Camillo Ricordi in 1989 (19). Although this islet isolation protocol has been slightly modified over recent years, according to the experience of different transplantation groups, the basic steps of the procedure remain the same: cleaning the pancreas and cannulation of pancreatic ducts, enzymatic perfusion, distension and digestion of the pancreas, followed by islet dilution, purification and culture (Figure 2) (31).

The process starts when the donated organ is received and assessed by an isolation team, and ends with the release of the isolated islets for transplantation or research by a quality control (QC) team. The first stage of the process is the cleaning of the pancreas, which consists in organ dissection and removal of the spleen, duodenum and any underlying fat. The next step consists of pancreatic distension and digestion, a process through which an enzyme which breaks up collagen chains (collagenase) is infused into the main pancreatic duct, leading to the disaggregation of the pancreatic tissue. The pancreas is then cut into 8 to 10 pieces and transferred to a Ricordi Chamber (19) containing 7-9 silicone beads and filled with collagenase solution for the digestion phase, which is facilitated by mechanical agitation. When islets are separated from the exocrine tissue and are not over-digested, large volumes of dilution solution are then added to the tissue to stop the digestion process. In the purification step, the islets are separated from the exocrine and ductal tissues through continuous or discontinuous density gradients using a COBE 2991 centrifuge. The goal of this step is to purify the islets that will be used in the transplant, throwing

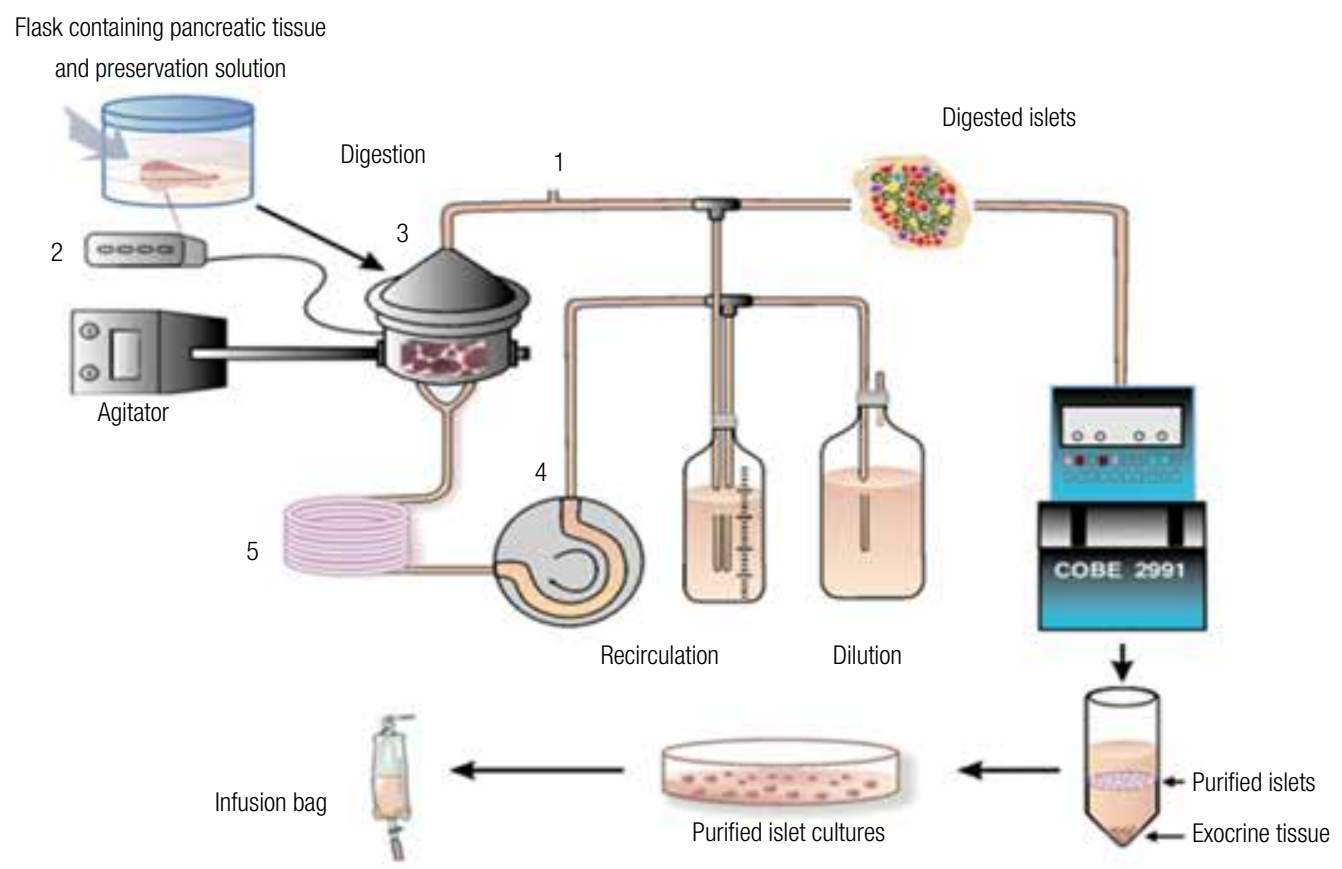

Figure 2. Pancreatic islet isolation and transplantation from the donor to the recipient. Adapted from reference $31 . \mathbf{1}=$ sampling location for islet collection and for the monitoring of digested islets; $\mathbf{2}=$ chamber temperature monitoring probe $\left(37^{\circ} \mathrm{C}\right) ; \mathbf{3}=$ Ricordi Chamber with silicone beads, pancreatic tissue and collagenase solution; $\mathbf{4}$ = peristaltic pump to ensure the circulation of the solutions in the system; $\mathbf{5}=$ heating coil in a $50^{\circ} \mathrm{C}$ water bath. 
away the remaining cells, so that only a small volume of tissue ( $10 \mathrm{~mL}$ maximum) will be infused into the portal vein, reducing the risk of portal vein hypertension and thrombosis (16). After isolation, islets are cultured for up to three days (32).

The FDA has stated that, before allogeneic islet transplantation is approved as a treatment option for TIDM, the safety, purity, potency and efficacy of the islets must be assessed. For islets to be considered suitable for transplantation, the islet isolation and purification processes must be defined, validated, and proved to be able to generate consistently high-quality products (33). Therefore, the last step in the isolation process consists of QC tests for purity, number of islet equivalents (IEQ - one IEQ corresponds to one islet with $150 \mu \mathrm{m}$ diameter or greater), viability, cell functionality and sterility (34).

Purity (the proportion of islets to other tissue types in the isolated material) is assessed throughout the stages of islet isolation and culture. Only the samples with purity $>50 \%$ can be approved for transplant. The IEQ is determined by the estimated diameter of islets. Transplantation is only possible if the IEQ is $>5000$ IEQ $/ \mathrm{kg}$ of the recipient's body weight, in a maximum volume of $5-10 \mathrm{~mL}$ (34). The viability of islets (number of live cells/total number of cells, including dead cells) is determined by the integrity of the cell membrane. This is assessed by staining tissue samples with two types of dye (fluorescein diacetate, which stains viable cells green, and propidium iodide, which stains damaged cells red), and examining the results in a fluorescent microscope (35). The islet batch is considered adequate for transplantation if its viability is over $80 \%$. Islet function is assessed by measuring the amount of insulin secreted after incubation with low and high concentrations of glucose and, then, calculating a stimulation index (SI) by dividing insulin concentration of the islet sample stimulated with high glucose by the insulin concentration of the islet sample stimulated with low glucose (20). Functional islets must have a SI $>1$. The sterility is assessed through aerobic and anaerobic bacterial cultures as well as mycoplasma and endotoxin tests $(16,34)$.

\section{ISLET TRANSPLANTATION AND THE CURRENT STATUS OF THIS PROCEDURE IN BRAZIL}

Pancreatic islet transplantations have proved to be a safe and effective treatment option for patients with "brittle TIDM". However, the clinical applicability of islet transplantation in many health centers is limited by the complexity of islet isolation processes, the high cost $(34,36)$ and the scarcity of donor organs $(37)$. Since each transplant patient generally requires islets isolated from two to three donors in order to improve rates of insulin independence (37), there is a significant interest in developing methods for isolating the greatest number of viable islets from the pancreas of each donor. However, this is a challenging process, which requires considerable experience with cell isolation procedures and an extensive knowledge of the factors which influence islet quantity and quality (38).

The physical, chemical and mechanical impacts suffered by the islets during the isolation process might lead to fragmentation and damage of the $\beta, \alpha, \delta$ and PP cells (39), influencing the quantity and quality of available islets. In the past 6 years, an additional obstacle was introduced into islet isolation research, as the most effective collagenase used in pancreatic digestion (Liberase HI, Roche Pharmaceutics) was removed from the market due to the discovery of an association between the enzyme and an increased risk of spongiform encephalopathy transmission (40). Other collagenases, such as Serva NBl (Serva, Heidelberg, Germany), Liberase MTF (Roche, Indianapolis, USA) and Vitacyte (CIzyme HA, Indianapolis, USA) (37,41-43) are promising alternatives for islet isolation (44). However, studies that have sought to assess which enzyme would be the most adequate for pancreatic digestion have produced conflicting results $(40,42,45-48)$. A metaanalysis conducted by our research group (49) found that all aforementioned enzymes lead to similar levels of islet quantity (IEQ/g pancreas) and quality (purity and viability); however, Vitacyte and Serva NBl enzymes seem to be associated with an improved SI as compared with Liberase MTF.

Donor characteristics (age, gender, medical history, body mass index [BMI], cause of death, use of vasopressor agents) and pancreas characteristics (size, fat content, duration of cold ischemia) may also influence the quality and quantity of the isolated islets $(30,50,51)$. Although organs donated by individuals with BMI > $25 \mathrm{~kg} / \mathrm{m}^{2}$ and/or age over 50 years tend to produce a greater number of islets, these islets do not always function adequately $(50,51)$. The study by Sá and cols. (53) reinforced the importance of the donor BMI as a defining parameter for successful islet isolation and established this variable as a potential pancreas alloca- 
tion criterion for pancreatic islet transplantation in Brazil. The duration of cold ischemia is also relevant to the islet isolation process, since increased cold ischemia time may damage the pancreatic tissue. Therefore, the type of solution used to preserve the pancreas and decrease the deleterious effects of hypoxia may have an important effect on transplant results (30). Most isolation procedures involve the use of the UW (University of Wisconsin) solution, which contains electrolytes and other substances that contribute to cell integrity (30). However, some studies have found that the combined use of UW solution and other substances with high oxygen affinity (two-layer perfluorocarbon method) led to improved pancreatic preservation $(54,55)$, although these results were most pronounced in cases of prolonged cold ischemia (56).

The effect of brain death (BD) on the pancreas may also influence the quality of the donated organ. A study conducted by our research group found that, in the case of $\mathrm{BD}$ donors, the pancreas appears to be damaged long before isolation, as evidenced by an increase in TNF levels in the organ (57). Another recent study has also found that the organs of $\mathrm{BD}$ donors produce islets of lower quality when compared to those whose donors died of heart-related causes (51).

As previously cited, one of the main limitations reported by most islet transplantation centers is a scarcity of BD donors (8). In Brazil, a report issued by the Brazilian Organ Transplant Association noted that only $6.3 \%(\mathrm{n}=80)$ of the total number of pancreases donated $(n=1273)$ were used in the first semester of 2013 (58). The remaining organs could have been used for islet isolation purposes, indicating an adequate supply of organs for islet transplantation in Brazil. In Brazil, there are two laboratories involved in islet isolation research, which, in the past, had also carried out islet transplants: the NUCEL (Nucleus of Cell and Molecular Therapy) in São Paulo, which is associated with the University of São Paulo (USP) and performed its first transplant in 2002 (59); and a laboratory in Curitiba (Paraná), associated with the PUC-Paraná University and the Pro-Kidney Foundation, which conducted one transplant in 2005 (60).

Nevertheless, the high costs involved in islet isolation still place a burden on this process. In 2004, a French study evaluated the cost of islet transplantation from the time of organ removal until the transplant itself and its follow-up. The study found that islet isolation was the most expensive phase of the process, accounting for $30 \%$ of total transplant costs (36). A similar situation has been reported in Brazil, where the reliance on imported isolation reagents may lead costs to rise even further $(61)$.

In light of these facts, a number of islet transplantation centers have focused on the development of different methods for islet isolation and, when possible, for the selection of organs that might be more adequate for transplantation and are more likely to produce positive results in terms of the quantity and quality of isolated islets and insulin independence in the long term $(37,57,60)$.

\section{BRAZILIAN LEGISLATION}

In the USA, the islet isolation process must follow the drug and biological product regulations issued by the FDA and the Public Health Service Act (62). In Brazil, there is still no specific legislation to regulate islet transplantation. However, both the construction of the isolation laboratories as well as the islet isolation process must follow RDC Resolutions Numbers 210 ("Good Practice in Drug Manufacturing", August $4^{\text {th }}$, 2003) and 9 ("Guidelines for the functioning of Cell Technology Centers involved in clinical research and treatment”, March 14 $4^{\text {th }}, 2011$ ) issued by the Agência Nacional de Vigilância Sanitária (Anvisa) $(63,64)$. RDC resolution number 9 divides cell therapy methods into two categories according to their purpose: autologous use and allogeneic cell manipulation. Islet transplantation procedures would be classified into the latter group.

\section{ISLET TRANSPLANTATION IN PATIENTS WITH "BRITTLE T1DM"}

Islet transplantation is generally recommended as a treatment option for patients with "brittle TIDM", which is defined by the presence of significant daily variations in capillary glycemia, typically higher than $200 \mathrm{mg} / \mathrm{dL}$, which might lead to significant impairment in quality of life and/or the occurrence of severe hypoglycemia without adrenergic symptoms $(6,65)$. In these patients, allogeneic islet transplantation tend to be performed in one of three ways depending on patient characteristics: 1) islet transplantation in non-uremic patients; 2) islet transplantation following kidney transplants in patients with end-stage kidney disease; and 3) simultaneous islet and kidney transplantations (66). 
To date, patients included in islet transplantation protocols have had the following characteristics: age between 18 and 65 years, TIDM for over 5 years with undetectable C-peptide concentrations, occurrence of severe recurrent hypoglycemia and progression of chronic complications associated with diabetes (30). In the Immune Tolerance Network study (22), the presence of untreated arterial disease, $\mathrm{BMI}>26 \mathrm{~kg} / \mathrm{m}^{2}$, the need for insulin doses $>0.7 \mathrm{UI} / \mathrm{kg}, \mathrm{HbAlc}>12 \%$, creatinine $>1.5 \mathrm{mg} / \mathrm{dL}$ and/or albuminuria $>300 \mathrm{mg} / 24 \mathrm{~h}$, as well as the presence of infections or psychiatric diseases were considered exclusion criteria for transplantations.

In islet transplantations, as in pancreas transplants, the persistence or reappearance of anti-islet antibodies has been found to be correlated with worse clinical outcomes and may be a key contributing factor to graft failure (67). However, patient characteristics may also influence transplant outcome. Younger patients with higher HbAlc levels, clinical profiles suggestive of insulin resistance and higher lipid serum levels in the pretransplant period are at greater risk of early graft loss $(68,69)$.

It is also important to note that the site of islet infusion used by most studies in the literature is the portal vein, which is not the most adequate place for cell infusion (70). It is estimated that $50-70 \%$ of islets are destroyed in the period immediately following the transplant, given the unique characteristics of the liver and the damaging effect of immunosuppressive drugs on insulin secretion and islet viability (71). Currently, other infusion sites and methods have been studied in an attempt to develop techniques that ensure a better engraftment of the islets. One example is the encapsulation, which allows for revascularization while sparing the islets from environmental damage (70).

\section{DEVELOPMENT OF A HUMAN ISLET ISOLATION LABORATORY IN THE HCPA}

In 2010, a new laboratory for human islet isolation was established at the Endocrine Division of HCPA with the goal of isolating islets for: 1) developing experimental studies to assess ways of increasing the quality and quantity of isolated islets; 2 ) studying functional $\beta$ cells in patients with different physiological and pathological features; and 3) performing islet transplantation in patients with "brittle TIDM". This center has conducted 28 human islet isolations and, in the near future, will begin a study of human islet transplantation in TIDM patients who had already undergone kidney transplantation.

This islet isolation laboratory takes up an area of $63.6 \mathrm{~m}^{2}$ in the Endocrine Division (Figure 3). The laboratory was built between 2008 and 2010, and its construction process followed the guidelines established in RDC regulations (numbers 134 and 210) issued by Anvisa (63), as well as recommendations provided by the islet transplantation team at the Diabetes Research Institute, University of Miami (EUA).

Positive internal pressure, use of air-conditioning with high efficiency particulated air (HEPA) filters, and restricted access policies in effect at the islet isolation laboratory are the same as those recommended for surgery rooms. The dressing room is kept at cleanliness Class 100.000 (up to 100.000 particles with a size of 0.5 microns or greater per $\mathrm{m}^{3}$ of air), while the remainder of the lab is kept at Class 10.000. The laboratory contains a dressing room for changing into sterile garments, a hand-rubbing area, a separate internal location for islet isolation and culture, a reagent storage room, a cold chamber and a laboratory exit chamber. All furniture in the laboratory is made of stainless steel to facilitate cleaning and prevent contamination. The laboratory is surrounded by a Cell and Molecular Biology Laboratory, a glassware sterilization room, and the QC center for the isolated islets, which contains a fluorescent microscope and an ELISA (enzyme-linked immunosorbent assay) micro-plate reader.

The core of the islet isolation team consists of a nephrologist and a biologist, both of whom are HCPA employees who received training in international reference centers. The nephrologist held her training in isolation of human, pig and mouse islets as well as in human islet transplantation at the Schulze Diabetes Institute (University of Minnesota, Minneapolis, EUA) for two years, while the biologist was trained in rat islet isolation and $\beta$ cell functionality at the Laboratory of Experimental Medicine of the Free University of Brussels (Brussels, Belgium) for one year. The team also includes an endocrinologist, who was trained in human islet isolation as well as monitoring and treatment of transplanted patients at the Diabetes Research Institute of the University of Miami (Florida, EUA) for a period of one year. The islet isolation team is assisted by undergraduate students, masters' and $\mathrm{PhD}$ students, a technical support assistant and a post-doctoral fellow, all of whom received scholarships from national research support agencies. A research project entitled "Establishment of a Human Pancreatic 
Islet Isolation Laboratory at the HCPA" was developed specifically for the purpose of constructing the laboratory and organizing an organ donation system. This project was approved by the Research Ethics Committee of HCPA (project number 08-131) and by the Transplant Center of the state of Rio Grande do Sul, Brazil. Any donated organs which are not used for whole-pancreas transplants or kidney-pancreas transplantation are used for islet isolation purposes once the donor's family signs an informed consent form provided by the Laboratory of Human Pancreatic Islet Biology. The surgical team responsible for organ removal is associated with the OPOS (Organ Procurement Organizations) of the Department of Health - Rio Grande do Sul.

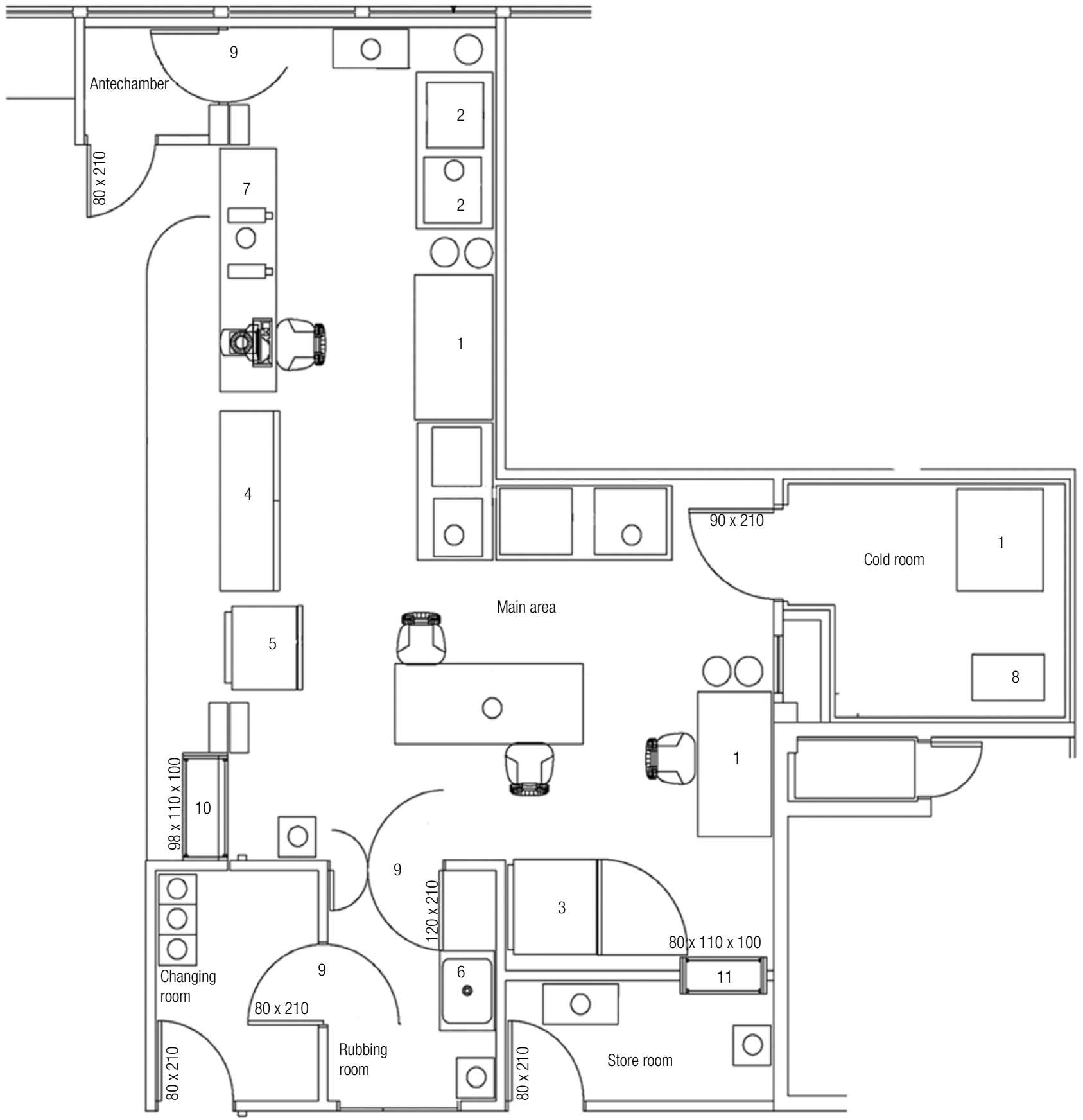

Figure 3. Floorplan of the Laboratory of Human Pancreatic Islet Biology - Endocrine Division - Hospital de Clínicas de Porto Alegre. $\mathbf{1}=$ Biological safety cabinets; $\mathbf{2}$ = Incubators; $\mathbf{3}=$ Freezer $-86^{\circ} \mathrm{C} ; \mathbf{4}=$ Refrigerator; $\mathbf{5}=$ Freezer $-20^{\circ} \mathrm{C} ; \mathbf{6}=$ Water bath; $\mathbf{7}=$ Microscope; $8=$ COBE $2991 ; \mathbf{9}=$ Door with glass window; $\mathbf{1 0}$ = Window for exiting of materials; $\mathbf{1 1}$ = Window for entering of materials. 


\section{CONCLUSIONS}

Pancreatic islet transplantation should be considered a useful treatment option for decreasing the occurrence of severe hypoglycemic episodes and improving glycemic control in patients with "brittle TIDM". In many countries, islet transplantation is already used as treatment for TIDM. However, in countries such as Brazil, this procedure is still carried out only as part of experimental research initiatives. Therefore, efforts must be made toward increasing the effectiveness of islet isolation and transplantation techniques, as well as post-transplant follow-up procedures, to ensure that islet transplantation will be eventually implemented as part of routine clinical practice.

The establishment of islet isolation laboratories is a slow and complex process, which requires significant financial investment. The Laboratory of Human Pancreatic Islet Biology at the Endocrine Division of the HCPA aims to provide human islets for research purposes and, in the near future, become a reference center for islet transplantation and $\beta$ cell research in Brazil.

Acknowlegments: This study was partially supported by grants from the Fundação de Amparo à Pesquisa do Estado do Rio Grande do Sul (Fapergs), the Conselho Nacional de Desenvolvimento Científico e Tecnológico (CNPq), the Fundo de Incentivo à Pesquisa e Eventos (Fipe) at the Hospital de Clínicas de Porto Alegre (HCPA) and Coordenação de Aperfeiçoamento de Pessoal de Nível Superior (Capes). MJB, SPS, JLG, CBL and DC are recipients of $\mathrm{CNPq}-\mathrm{PQ}$ scholarships.

Disclosure: no potential conflict of interest relevant to this article was reported.

\section{REFERENCES}

1. Diagnosis and classification of diabetes mellitus. Diabetes Care. 2013;36 Suppl 1:S67-74.

2. Pugliese A, Skyler JS. George S. Eisenbarth: insulin and type 1 diabetes. Diabetes Care. 2013;36(6):1437-42.

3. Langendam M, LuijfYM, Hooft L, Devries JH, Mudde AH, Scholten RJ. Continuous glucose monitoring systems for type 1 diabetes mellitus. Cochrane Db Syst Rev. 2012;1:CD008101.

4. The effect of intensive treatment of diabetes on the development and progression of long-term complications in insulin-dependent diabetes mellitus. The Diabetes Control and Complications Trial Research Group. N Engl J Med. 1993;329(14):977-86.

5. Kobayashi N. The current status of islet transplantation and its perspectives. Rev Diabet Stud. 2008;5(3):136-43.

6. Ryan EA, ShandroT, Green K, Paty BW, Senior PA, Bigam D, et al. Assessment of the severity of hypoglycemia and glycemic lability in type 1 diabetic subjects undergoing islet transplantation. Diabetes. 2004;53(4):955-62.

7. Ichii $\mathrm{H}$, Ricordi C. Current status of islet cell transplantation. J Hepato-Biliary-Pan. 2009;16(2):101-12.
8. Leitao CB, Tharavanij T, Cure P, Pileggi A, Baidal DA, Ricordi C, et al. Restoration of hypoglycemia awareness after islet transplantation. Diabetes Care. 2008;31(11):2113-5.

9. Gruessner RW, Sutherland DE, Kandaswamy R, Gruessner AC. Over 500 solitary pancreas transplants in nonuremic patients with brittle diabetes mellitus. Transplantation. 2008;85(1):42-7.

10. Vardanyan M, Parkin E, Gruessner C, Rodriguez Rilo HL. Pancreas vs. islet transplantation: a call on the future. Curr Opin Organ Tran. 2010;15(1):124-30.

11. Barton FB, Rickels MR, Alejandro R, Hering BJ, Wease S, Naziruddin $B$, et al. Improvement in outcomes of clinical islet transplantation: 1999-2010. Diabetes Care. 2012;35(7):1436-45.

12. Williams $P$. Notes on diabetes treated with extract and by grafts of sheep's pancreas. Br Med J. 1894;2:1303-4.

13. Lacy PE, Walker MM, Fink CJ. Perifusion of isolated rat islets in vitro. Participation of the microtubular system in the biphasic release of insulin. Diabetes. 1972;21(10):987-98.

14. Najarian JS, Sutherland DE, Baumgartner D, Burke B, Rynasiewicz JJ, Matas AJ, et al. Total or near total pancreatectomy and islet autotransplantation for treatment of chronic pancreatitis. Ann Surg. 1980;192(4):526-42.

15. Robertson RP, Lanz KJ, Sutherland DE, Kendall DM. Prevention of diabetes for up to 13 years by autoislet transplantation after pancreatectomy for chronic pancreatitis. Diabetes. 2001;50(1):47-50.

16. Robertson RP. Islet transplantation as a treatment for diabetes - a work in progress. N Engl J Med. 2004;350(7):694-705.

17. Leitao CB, Cure P, Tharavanij T, Baidal DA, Alejandro R. Current challenges in islet transplantation. Curr Diabetes Rep. 2008;8(4):324-31.

18. Brendel MD HB, Schultz AO, Bretzel RG. International Islet Transplant Registry Newsletter 9, 2001.

19. Ricordi C, Lacy PE, Finke EH, Olack BJ, Scharp DW. Automated method for isolation of human pancreatic islets. Diabetes. 1988;37(4):413-20.

20. Shapiro AM, Lakey JR, Ryan EA, Korbutt GS, Toth E, Warnock GL, et al. Islet transplantation in seven patients with type 1 diabetes mellitus using a glucocorticoid-free immunosuppressive regimen. N Engl J Med. 2000;343(4):230-8.

21. Ryan EA, Paty BW, Senior PA, Bigam D, Alfadhli E, Kneteman NM, et al. Five-year follow-up after clinical islet transplantation. Diabetes. 2005;54(7):2060-9.

22. Shapiro AM, Ricordi C, Hering BJ, Auchincloss H, Lindblad R, Robertson $\mathrm{RP}$, et al. International trial of the Edmonton protocol for islet transplantation. N Engl J Med. 2006;355(13):1318-30.

23. Johnson PRV. Challenges in setting up a new islet transplant program. Islet Transplantation and Beta Cell Replacement Therapy. In: Shapiro AMJ. 2007;203-14.

24. Shapiro AM. Islet transplant activity (1999-2011). Edmonton AB Presentation, 2010.

25. Scuteri JFL, O'Mahony CA, Lewis S, Shapiro AMJ. Health Technology Assessment of proposal to establish the islet transplantation procedure as a nationally funded centre. Assessment ReportDraft. Health Consult Pty Ltd, 2011.

26. Lehman R, Gerber PA. End-stage nephropathy in type 1-diabetes mellitus - kidney transplantation alone or combined with islet or pancreas transplantation? Ther Umsch. 2011;68(12):699-706.

27. Mineo D, Pileggi A, Alejandro R, Ricordi C. Point: steady progress and current challenges in clinical islet transplantation. Diabetes Care. 2009;32(8):1563-9.

28. Shapiro AM. Islet transplantation in type 1 diabetes: ongoing challenges, refined procedures, and long-term outcome. Rev Diabet Stud. 2012;9(4):385-406.

29. Maffi P, Scavini M, Socci C, Piemonti L, Caldara R, Gremizzi C, et al. Risks and benefits of transplantation in the cure of type 1 
diabetes: whole pancreas versus islet transplantation. A single center study. Rev Diabet Stud. 2011;8(1):44-50.

30. Correa-Giannella ML, Raposo do Amaral AS. Pancreatic islet transplantation. Diabetol Metab Syndr. 2009;1(1):9-10.

31. Merani S, Shapiro AM. Current status of pancreatic islet transplantation. Clin Sci (Lond). 2006;110(6):611-25.

32. Kin T, Senior P, O'Gorman D, Richer B, Salam A, Shapiro AM. Risk factors for islet loss during culture prior to transplantation. Transplant Int. 2008;21(11):1029-35.

33. Linetsky E, Ricordi C. Regulatory challenges in manufacturing of pancreatic islets. Transplant Proc. 2008;40(2):424-6.

34. Yamamoto T, Horiguchi $A$, Ito $M$, Nagata $H$, Ichii $H$, Ricordi $C$, et al. Quality control for clinical islet transplantation: organ procurement and preservation, the islet processing facility, isolation, and potency tests. J Hepato-Biliary-Pan. 2009;16(2):131-6.

35. Barnett MJ, McGhee-Wilson D, Shapiro AM, Lakey JR. Variation in human islet viability based on different membrane integrity stains. Cell Transplant. 2004;13(5):481-8.

36. Guignard AP, Oberholzer J, Benhamou PY, Touzet S, Bucher P, Penfornis $A$, et al. Cost analysis of human islet transplantation for the treatment of type 1 diabetes in the Swiss-French Consortium GRAGIL. Diabetes Care. 2004;27(4):895-900.

37. McCall $M$, Shapiro AM. Update on islet transplantation. Cold Spring Harbor Perspectives in Medicine. 2012;2(7):a007823.

38. Shapiro AM. Strategies toward single-donor islets of Langerhans transplantation. Curr Opin Organ Tran. 2011;16(6):627-31.

39. Rosenberg L, Wang R, Paraskevas S, Maysinger D. Structural and functional changes resulting from islet isolation lead to islet cell death. Surgery. 1999;126(2):393-8.

40. Linetsky E, Bottino R, Lehmann R, Alejandro R, Inverardi L, Ricordi C. Improved human islet isolation using a new enzyme blend, liberase. Diabetes. 1997;46(7):1120-3.

41. Szot GL, Lee MR, Tavakol MM, Lang J, Dekovic F, Kerlan RK, et al. Successful clinical islet isolation using a GMP-manufactured collagenase and neutral protease. Transplantation. 2009;88(6):753-6.

42. O'Gorman D, KinT, Imes S, Pawlick R, Senior P, Shapiro AM. Comparison of human islet isolation outcomes using a new mammalian tissue-free enzyme versus collagenase NB-1. Transplantation. 2010;90(3):255-9.

43. Brandhorst $H$, Friberg $A$, Nilsson $B$, Andersson $H H$, Felldin $M$, Foss $\mathrm{A}$, et al. Large-scale comparison of Liberase $\mathrm{HI}$ and collagenase NB1 utilized for human islet isolation. Cell Transplant. 2010;19(1):3-8.

44. Balamurugan AN, Loganathan G, Bellin MD, Wilhelm JJ, Harmon $J$, Anazawa T, et al. A new enzyme mixture to increase the yield and transplant rate of autologous and allogeneic human islet products. Transplantation. 2012;93(7):693-702.

45. Misawa R, Ricordi C, Miki A, Barker S, Molano RD, Khan A, et al. Evaluation of viable beta-cell mass is useful for selecting collagenase for human islet isolation: comparison of collagenase NB1 and liberase HI. Cell Transplant. 2012;21(1):39-47.

46. Shimoda M, Noguchi H, Naziruddin B, Fujita Y, Chujo D, Takita M, et al. Assessment of human islet isolation with four different collagenases. Transplant Proc. 2010;42(6):2049-51.

47. Iglesias I, Valiente L, Shiang KD, Ichii H, Kandeel F, Al-Abdullah IH. The Effects of Digestion Enzymes on Islet Viability and Cellular Composition. Cell Transplant. 2012;21(4):649-55.

48. Sabek OM, Cowan P, Fraga DW, Gaber AO. The effect of isolation methods and the use of different enzymes on islet yield and in vivo function. Cell Transplant. 2008;17(7):785-92.

49. Rheinheimer J, Ziegelmann PK, Carlessi R, Reck LR, Bauer AC, Leitão $C B$, et al. Different digestion enzymes used for human pancreatic islet isolation: a mixed treatment comparison (MTC) metaanalysis. Islets. 2014;6(4):e977118.

50. Sakuma Y, Ricordi C, Miki A, Yamamoto T, Pileggi A, Khan A, et al. Factors that affect human islet isolation. Transplant Proc. 2008;40(2):343-5.
51. Hilling DE, Bouwman E, Terpstra OT, Marang-van de Mheen PJ. Effects of donor, pancreas and isolation-related variables on human islet isolation outcome: a systematic review. Cell Transplant. 2014;23(8):921-8.

52 Ponte GM, Pileggi A, Messinger S, Alejandro A, Ichii H, Baidal DA, et al. Toward maximizing the success rates of human islet isolation: influence of donor and isolation factors. Cell Transplant. 2007;16(6):595-607.

53. Sá GPD, Sogayar MC, Eliaschewitz FG, Genzini T, Letrinta R, Onari $\mathrm{SE}$, et al. Islet vs. pancreas transplantation in Brazil "Defining criteria for pancreas allocation decision". Islets. 2011;3(6):352-7.

54. Caballero-Corbalan J, Eich T, Lundgren T, Foss A, Felldin M, Kallen $\mathrm{R}$, et al. No beneficial effect of two-layer storage compared with UW-storage on human islet isolation and transplantation. Transplantation. 2007;84(7):864-9.

55. TsujimuraT, KurodaY, ChurchillTA, Avila JG, KinT, Shapiro AM, et al. Short-term storage of the ischemically damaged human pancreas by the two-layer method prior to islet isolation. Cell Transplant. 2004;13(1):67-73.

56. Qin $\mathrm{H}$, Matsumoto $\mathrm{S}$, Klintmalm GB, De Vol EB. A meta-analysis for comparison of the two-layer and university of Wisconsin pancreas preservation methods in islet transplantation. Cell Transplant. 2011;20(7):1127-37.

57. Rech $T H$, Crispim D, Rheinheimer J, Barkan SS, Osvaldt AB, Grezzana Filho TJ, et al. Brain death-induced inflammatory activity in human pancreatic tissue: a case-control study. Transplantation. 2014;97(2):212-9.

58. Associação Brasileira de Transplante de Órgãos. Available at: www.abto.org.br. Accessed on: Feb, 2014.

59. Eliaschewitz FG, Aita CA, GenziniT, Noronha IL, Lojudice FH, Labriola $\mathrm{L}$, et al. First Brazilian pancreatic islet transplantation in a patient with type 1 diabetes mellitus. Transplantat Proc. 2004;36(4):1117-28.

60. Percegona LS, Aita CA, Pereira E, Sotta ED, Silva IC, Riella MC. Clinical protocol for selection of the candidates for islet transplantation. Arq Bras Endocrinol Metabol. 2008;52(3):506-14.

61. Rheinheimer J. Transplante de ilhotas pancreáticas humanas: revisão da literatura e implantação de um laboratório de isolamento de ilhotas pancreáticas. Clin Biomed Res. 2010;30(4):407-18.

62. Wonnacott K. Update on regulatory issues in pancreatic islet transplantation. Am JTher. 2005;12(6):600-4.

63. ANVISA. RDC $N^{\circ} 210$ - Boas Práticas de Fabricação de Medicamentos. Agência Nacional de Vigilância Sanitária, 2010.

64. ANVISA. RDC N 9. Agência Nacional de Vigilância Sanitária, 2011.

65. Shalitin S, Phillip M. Hypoglycemia in type 1 diabetes: a still unresolved problem in the era of insulin analogs and pump therapy. Diabetes Care. 2008;31 Suppl 2:S121-4.

66. Ricordi C, Strom TB. Clinical islet transplantation: advances and immunological challenges. Nat Rev Immunol. 2004;4(4):259-68.

67. Huurman VA, Hilbrands R, Pinkse GG, Gillard P, Duinkerken G, van de Linde $P$, et al. Cellular islet autoimmunity associates with clinical outcome of islet cell transplantation. PloS One. 2008;3(6):e2435.

68. Leitao CB, Bernetti K, Tharavanij T, Cure P, Lauriola V, Berggren $\mathrm{PO}$, et al. Lipotoxicity and decreased islet graft survival. Diabetes Care. 2010;33(3):658-60.

69. Leitao CB, Bernetti K, Tharavanij T, Cure P, Ricordi C, Alejandro R. Type 2 diabetes mellitus phenotype and graft survival after islet transplantation. Transplantation. 2009;88(1):57-61.

70. Smink AM, Faas MM, de Vos P. Toward engineering a novel transplantation site for human pancreatic islets. Diabetes. 2013;62(5):1357-64.

71. Shapiro AM, Ryan EA, Lakey JR. Diabetes. Islet cell transplantation. Lancet. 2001;358 Suppl S21. 